Special Meeting.

June 28th, 1887.

The meeting was called to order at 8 P. M., at Martinelli's, 136 Fifth Avenue, New York, by the President, Mr. T. C. Martin, who announced the subject for discussion as Electric Train Lighting, and introduced Mr. George W. Blodgett, Electrician of the Boston and Albany Railroad, who had prepared a paper for the meeting.

Mr. Blodgett :-Mr. President and Gentlemen; I highly appreciate the honor you have done me in asking me to read a paper upon this somewhat new and important subject of "The Electric Lighting of Passenger Trains." It is to me, to some extent, an unsolved problem still to be worked out, so if you should say to ne at the end of my paper, you are not well informed upon the subject, I should feel like saying, neither are any of us. It is in some points at least a subject of which we all know very little.

\title{
THE ELECTRIC LIGHTING OF PASSENGER TRAINS.
}

BY GEO. W. BLODGETT.

A better method of lighting passenger trains is demanded by considerations of economy, comfort and safety. Economy is a question which chiefly concerns the railroad management, but comfort and safety concern all its patrons. There are two ways in which we may seek these; either by improving the presentsystem or by substituting a better one. It is doubtful whether oil lighting can be much improved and still be reasonable in cost, and whatever danger attends its use would probably still remain. I have made careful inquiry among my railroad friends without finding any instance within their personal knowledge where the ruins of a railroad wreck were set on fire by the lamps in the train (indeed these are usually instantly extinguished), but such an instance was said by one of the surrivors to have occurred in the late disaster at Hartford, Vt., and another was mentioned at 
a recent meeting of the New England Railroad Club, where the explosion of a lamp set a sleeping car on fire, and it burned with nearly all the occupants. It is, however, certain that a pile of splinters deluged with oil will burn more fiercely and be much more difficult to extinguish, than if in its normal condition.

It is therefore desirable to get rid of oil lamps, for the harm they may do in aiding the progress of a fire, even if they do not cause one. The discomforts of oil lighting, in point of amount, distribution, unsteadiness and color of the light, corruption of the air, and the great heat given out by a large number of lamps in a car are other reasons why a change would be welcome to both the railroad management and the public, if a reliable substitute can be found. Some of the objections enumerated above apply with equal force to lighting by gas, the others are partially, but not wholly eliminated. Electricity, however, offers a means of lighting which comes nearer to meeting all the requirements of a perfect light for passenger cars than any other yet discovered.

There are several ways in which we may produce the electricity for car lighting. It is possible to light a car successfully by any one of them, but further experiment is necessary to determine which is the very best to adopt, and we have already found some much better adapted than others to our American trains. The different methods will be considered in order.

1. By batteries. I know only one experiment successfully going on at present. A train has been running for nearly a year between Paris and Brussels, the cars of which are lighted by electricity from a bichromate battery. It lasts for five trips of seven hours each - that is, 35 hours of lighting -without renewal, which is said to take only five minutes. No accurate estimate of cost, or more detailed information is yet at hand. There are several other batteries in the market which appear well, and if the motion of the train does not have a deleterious effect, would seem possibly adapted to this work. My own experience is conversant with only one trial of this kind which did not succeed. Forty cells of a battery which had worked well in several house installations were put in boxes suspended from the bottom of a car, and 16 lamps of $16 \mathrm{c}$. p. each, put up in the car. The lamps burned well for one night but the next night there was the appearance of a sudden and enormous increase of interrial resistance in the battery, and it was removed for further experiment before trying to light cars. An attempt was made two or three months ago, to light a 
N. Y. C. passenger car with batteries of some kind, which also failed as I am told. [Note A.]

2. By a dynamo machine. There are three ways in which this has been done. A small dynamo and engine have been mounted on the boiler or tender, and the latter run by steam from the locomotive boiler. The great objection to this method is that there is no light before the engine is attached to the train, nor if it be temporarily removed. To obviate this difficulty a separate boiler, engine and dynamo have sometimes been carried in the baggage car or on a platform car at the head of the train. It would seem that the danger from fire in this arrangement would be quite as great as by the stoves in the cars. A method tried with some success in a few instances in England and elsewhere abroad (but only once in this country to my knowledge), is to run the dynamo from one of the axles of the train, the proper speed being obtained by suitable countershafting and belts between the axle and the pulley of the dynamo. Since there would be no light when the train is at rest or when the dynamo was running at too low a speed, a battery of accumulators is added, sufficient: to keep the lamps lighted for the longest time when the train is standing in the station, or elsewhere. When the train stops, or is at too low a speed for the dynamo to light all the lamps, they are automatically switched to the circuit of the accumulators where they remain till sufficient speed is again attained when they are switched back on the dynamo circuit. During the day, when the train is running, the dynamo charges the accumulators and keepo. them full. They are sufficient to light the train several hours if need be. On one train, in Germany, the dynamo and 26 aecumulators weighed 1,350 pounds, and cost about $\$ 625$; operating about twelve lamps, cost about two cents per hour, or onesixth of a cent per lamp per hour. The London, Brighton and South Coast Railway Co. fitted up four traine in this way. In one train of eleven cars there are thirty-two $16 \mathrm{c}$. p. lampe, absorbing forty amperes of current. The acenmulators are stated to hold 500 amperes (probably 500 ampere-hours is meant); and

Notr A.-Most batteries furnish a continuous current for so short a timewithout renewal, that their use is debarred on this account. Some others will not bear the shaking up produced by the motion of the train. I have myself experimented for a considerable time, but thus far without finding a battery which will run on a closed circuit longer than two or three weeks, and at the same time can be carried on a train. When such a one can be found, which at: the same time gives a current strong enough to light a series of lamps, it will have a great field of usefulness. 
when fully charged are stated to be sufficient to maintain the lamps for eight hours. This train has been running since December 19th, 1883; during the first eleven months it made 2,352 trips, and ran 27,322 miles. No failures are reported. A train on the South Eastern Railway has even run a longer distance. The dynamos on these trains have an E. M. F. of 45 volts and give 56 amperes of current. Two pairs of brushes are mounted on a rocking frame, so contrived, that when the train runs in one direction, by means of a lever loosely connected with the dynamo axle, and varied in position by attraction of the pole pieces of the field magnets, it tilts the frame in the direction to bring one pair of brushes in contact with the commutator. If the train runs in the opposite direction, the other pair of brushes is brought to bear on the commutator. A vessel, containing mercury, has revolving within, a coarse threaded screw driven by a belt from the dynamo-axle. At each end of the vessel is a vertical tube, at the upper end of which is an adjustable contact screw. When the dynamo and, consequently, the screw revolves in one direction, the mercury rises in one tube. If the motion is reversed, it rises in the other tube, and when it makes contact with the adjustable screw, the shunt circuit of the dynamo is joined up, the field magnets are charged, the lever is drawn up, and one pair of brushes brought to bear on the commutator, which completes the circuit for charging the accumulators. When the lamps are lighted and the train is in motion, the dynamo feeds them, the accumulators merely acting as a regulator. If more current is being generated than the lamps require, it goes to the accumulators. If less, the balance is given out by them. When the speed of the train slackens, the fall of mercury in one of the tubes breaks contact with the adjustable screw, the field magnet circuit is broken and the brushes, are removed from the commutator, the lamps continuing lighted by nieans of the current from the accumulators.

The apparatus can be used for several weeks with no attention beyond lubrication, and at the end of this period only a re-adjustment of the commutator brushes is necessary, which puts the machine in condition for a like longer period. The weight of the apparatus is about two tons.

The connections between the cars are made by coupling two cables together. A slightly different arrangement of circnits has the field magnets of the dynamo wound with two wires in oppo- 
site directions, one of which is in shunt to the armature, as if the dynamo was an ordinary shunt machine. The other is wound in the reverse direction, as if the dynamo were a compound machine, and the accumulators are in series with this wire. The lamps are also in shunt with the armature.

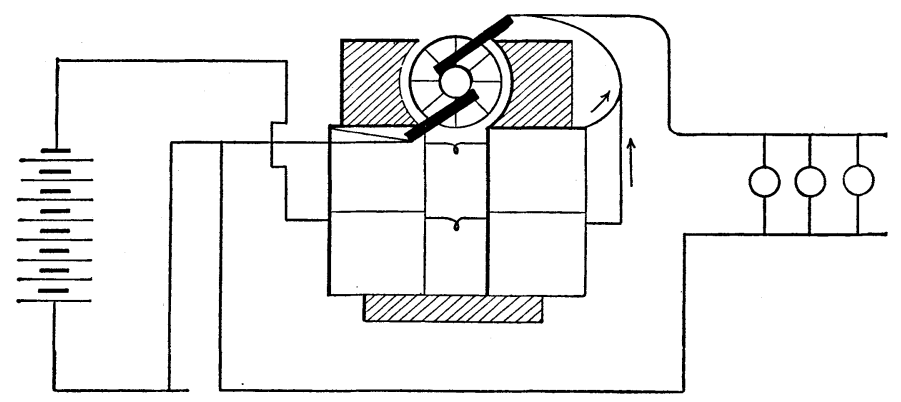

There is a cut-out to break the circuit of the armature when the dynamo runs below a certain speed; this prevents the cells discharging themselves through it and burning it out. If the dynamo does not furnish current enough for the lamps, the accumulators supply the balance, and in doing so, strengthen the field magnets and cause an increase of current in the dynamos. When this reaches a greater amount than that needed by the lamps, the surplus goes to the accumulators, and at the same time decreases the magnetism in the field magnets so as to preserve the balance. At the maximum speed of the machine, the cells are receiving their maximum charge, and the current to the lamps is of normal amount. Two sets of brushes are here necessary, as in the other case. Mr. Barrett, of Springfield, Mass., has fitted a train of three cars on the Connecticut River Railroad, with electric lights, to be run from a dynamo in something the same way as these just described. The peculiar arrangement of the trucks under an American car renders it a matter of difficulty to obtain the proper speed of the dynamo, and I am told Mr. Barrett has had much trouble with the connections between the axle and counter-shaft. If these are not kept tight the cable slips. If too tight it breaks. An ingenious device like a friction clamp transmits the power from the counter-shaft axle to a pulley upon it. This is governed. by centrifugal weights balanced by stiff springs. When the dynamo runs at its normal speed these just balance the friction of the clamp and there is no slip. Any increase of speed then causes 
the friction to diminish, and the pulley slips upon the shaft, till equilibrium is restored. Twenty-four Julien accumulators are connected with the circuit as a regulator, and to keep the lamps lighted when the train stops. A centrifugal governor breaks the circuit of the accumulators when the speed slackens.

A third arrangement of electric car lighting is by accumulators on the train, to be charged by a dynamo at a central station or terminus of the road. In England, a Pullman train has been running some years, lighted by electricity supplied by accumulators charged when the train is at rest, by a dynamo driven by a gas engine. The Pennsylvania Railroad Co. experimented more than two years ago with accumulators charged at one end of the line. When the train arrived at Jersey City, the trays containing the cells were removed from the car to a charging room, their places being supplied by spare cells previously charged. The empty ones were charged, to be replaced in the first car needing its batteries changed, and these in turn to some other car. The changing of the cells in a car took about 10 minutes. These experiments were in the main satisfactory, but the weak point was the life of the cells, the plates of which after a time buckled and fell to pieces. These cells were furnished by the Brush Electric Co. for these experiments ; but they declined to send out any more to be used in the same way until the Pennsylvania railroad experiments should be ended.

The estimated cost of fitting a car with ten lamps and batteries for 70 ampere hours was about $\$ 300$ per car.

In the month of January of the present year, the Julien Electric Co. placed 60 cells of their accumulators in boxes, on car No. 90 of the Boston and Albany Railroad, and put ten $16 \mathrm{c}$. p. lights in the car. These proved to be insufficient and the number was afterwards increased to 24, of which 20 were on the car and four over the platforms. This car was run some two months, as an experiment, with such excellent results that in March and April the trains leaving Boston and New York at 4:30 P. M. every day were fitted up with the same system. (These trains are also heated with steam from the locomotive, and there are no fires or oil lamps in any of the cars.) Each coach and parlor car is fitted with twenty-two 16 c. p. incandescent lamps, of which two, are over the platforms, 16 in the body of the car and the rest in the vestibules and toilet rooms. The lamps in the car are arranged opposite each other in two rows in the top of the car, and are on two 
circuits entirely independent of each other, each of which has a switch of its own by which the lamps may be turned on or off. The platforms are so arranged as to be lighted from either end of the car. They may, if desired, be lighted only just before reaching a station and extinguished just after leaving it.

Sixty cells of Julien accumulators are arranged in boxes under the car, 30 cells on each side. The weight is about one ton. The boxes are neat and ornamental in appearance, and the 30 cells on each side of the car are entirely independent of those on the other side, and are separately wired as far as the switch-board.

The cells have a capacity of 150 ampere hours and 60 volts on each side of the car. As 60-volt lamps are used, the accumulators on either side of the car will run all the lamps, but of course for only half the time the whole will do it. They are arranged in trays of six cells each, furnished with handles; they weigh 200 pounds and can be raised from the ground and put in the car by two men. The trays are fitted on the outside with stiff brass springs, which, when the trays are in place bear against each other, and form the connection between each tray and the next. When the trays are in place in the boxes the connections are all made. There are, therefore, no wires to disjoin or connections to make when it is desired to remove a tray for examination or otherwise. From the boxes on each side of the car, wires are'carried underneath the car to a switch-board in one of the toilet rooms, which also receives the terminals of the lamp circuits. The switch-board is so arranged that the number of cells in use can be varied from 27 in series to 30 in series, the others being added from time to time, to keep up the candle-power of the lamps, as the E. M. F. of the cells falls. Experiments are now being made to do away with the necessity for this, and if it is found practicable, it will be discontinued.

Two terminals underneath the middle of the car on either side serve to connect, by means of plugs, a pair of cables connected with wires leading to a dynamo in a lighting station a little way off. These terminals are of different size, so that no mistake can be made in the connections. When the accumulators are charged the whole 60 cells are placed in series; when they are connected to the lamps there are two series of 30 cells coupled together. In order that there should be no confusion or errors in doing this, I designed a switch which should, by a single movement in one direction, of four levers coupled together, throw all the cells in se- 
ries and connect them to the dynamo circuit. In this position they are entirely detached from the lamp circuits and no current can pass to the lamps. When this switch is thrown in the opposite direction the cells are cut off from the dynamo, coupled in two series of 30 cells each, and connected to the lamp circuits, which, however, do not light until turned on by the special switches for that purpose.

It is quite unlikely that an accident to either of the lamp circuits or the batteries on one side of the car would disable the other. By turning out the lamps on one circuit, therefore, the others may usually be kept burning till the train arrives at its destination. In two instances this arrangement of circuits has proved very valuable.

All the cars, except one, are fitted with Weston incandescent lamps said to take 1.1 amperes. The remaining car has Edison lamps, which are proving so satisfactory that it is quite probable all new work will be equipped with the Edison apparatus.

When the train arrives at Boston, it is put on a side track near which a line of poles has been set, and the dynamo wires strung upon them. Opposite each car a pair of terminals serves to make connection with the car, and the charging begins. A current of 18 amperes is run in for several hours, dropping to 12 and sometimes 10 amperes towards the end of the charge, which is now 180 ampere hours, to the 60 cells in series. If there were no loss, we could draw out 360 ampere hours in the lamps. Assuming that the lamps use 1.1 amperes each, we actually use about $22 \times 1.1$ ampere $\times 9$ hours = about 216 ampere hours or 60 per cent. of what is put in. If the lamps are required an extra hour or two, there is plenty of reserve for them. [Note B.] The attempt was made to reduce the charge to 140 or 130 ampere hours, but as some of the batteries were not in first-class condition, the results were not good.

The intention is always to have surplus of current in the battery. For the present the trains run a round trip to New York and return with one charging, but it is not yet quite certain that it can be done in the long nights of winter.

Note B.-Mr. A. Reckenzaun in a recent article on storage batteries gives the average efficiency as not less than 70 per cent. The Julien company claim, I understand, 80 to 85 per cent. for theirs. Doubtless this can be realized under special conditions, but my own experience would not warrant me in assuming o much in car lighting, - at least until the most favorable conditions of use are better understood. 
The cost of fitting these cars with accumulators and lamps was, when complete, about $\$ 900$ per car. Others fitted in the same way would cost less, as on this work the men were all inexperienced and there were no plans or precedents. The cost of operating the lights is not far from $\$ 2$ per car per day, or about one cent per hour per lamp. When the lights are needed a longer time, as in the dark days of winter, the cost per lamp hour would diminish. This is about ten times that of oil, and very nearly the same as for gas, but taking into consideration the amount of light obtained, electricity is the cheapest of the three, and immeasurably the most convenient. The light is very brilliant, well diffused, steady, and satisfactory beyond all expectations. A very noticeable feature of these cars is, the entire absence of heat, and the purity of the air, which is as fresh and sweet in the car at the end of its trip as before it leaves the first station; this, together with the absence of danger from fire, especially commends it for sleeping cars. The Electrical Accumulator Co. have also lighted some cars with success, for the Fitchburg and Old Colony Railroads, at Boston.

The electric light has come to stay. It is the only one which anywhere near fills the conditions of a satisfactory light for railway trains. It can be readily adapted to almost any conditions to be met with in practice.

Oil lamps, and stoves in cars, must follow where the old couplers and hand brakes for passenger trains have gone in this country, until electricity and steam heat have made the roasting alive of scores of people pinned fast in a railroad wreck as impossible as the air brake and Miller platform have made the telescoping of a train into a shapeless mass of ruins, as happened formerly so often. Not many years hence, we may well hope, one will be as uncommon as the other.

Dis CUS I I N.

The President :-The paper is now before the meeting for comment, criticism and discussion. Mr. Blodgett has had, as you have heard, very practical experience with the work and will be happy to answer any questions which may be put to him in regard to any of the details.

The Secretary :-I had the pleasure of coming from Boston, a week ago to-night, in a train equipped with the system which Mr. Blodgett has described so successfully, and having in view the fact that this paper was to come before our meeting, I per- 
haps gave the lights more attention than I otherwise would. The first and most noticeable feature of the installation to my mind was the fact that it appeared to be permanent. It was not experimental in the sense that so much electrical lighting has been, which we have all seen. Wires may have been there, but they were not visible. The lighting of the cars was certainly the best general lighting that I have seen with the exception, perhaps, of the Electrical Exposition at Philadelphia. The cars were lighted up in the station before leaving Boston at 4.30 in the afternoon, as it was rather dark in the building at that hour. That was the first advantage I saw. Although early in the summer afternoon, when artificial light is usually unnecessary, it was very easy to turn the lights on to give good illumination while the cars were temporarily in the station. After leaving the station, they were turned off, not being required again until nightfall. I think we reached the darkness about Hartford, and not having the scenery to gaze on, I turned to a book I had with me, and was very much pleased to find I could pass the time pleasantly with reading, without any strain on my eyes; and one curious feature of it was that, being absorbed in my book and having been looking out of the window for three or four hours, I turned once or twice to look out, and was surprised to find it was dark outside; there was nothing to look at. I had almost lost sight of the fact that it was artificial illumination, and this was certainly a very pleasant feature to think that I could read by a light as perfect as daylight, and possibly more perfect than some daylight that is quite common on the other side of the water. The lights are turned on in going through tunnels, or when you come to dark stations, which I consider a very desirable feature. The element of safety is one that is particularly noticeable, because we have heard so much of the dangers of fire from electric lighting. Now, however, when it comes to requiring safety from fire on railway trains, our experts turn to electric lighting, as the only resource; and there is no doubt but that danger from fire is entirely eliminated by the use of incandescent lights from storage batteries as they appear on that line. I am contrasting the wiring of this installation very favorably with another installation of car lighting which I saw on the same trip, where the wiring in both baggage and passenger cars bore evidence of having been done by some bungling telegraph lineman who had just started in the business. The expense the Boston and Albany Railroad Company has incurred in introducing 
these improvements reflects a great deal of credit on the progressive management of that road.

The President :-I would like to ask Mr. Blodgett a question. You stated in the course of your paper, Mr. Blodgett, that the cost of electric lighting was ten times that of oil. I would like to have it specifically stated, if you can do so, whether that applies to the whole of the apparatus or simply to the service.

Mr. BlodgetT :-My figures in relation to the cost of oil lighting were taken from a report by the Master Car Builders Association-possibly ten years ago. $\mathrm{My}$ impression is that in this report they took into account only the actual consumption of oil for lighting, and that no account was made of the cost or the care of the lamps or their renewal, or anything of that kind. Their figures show that oil lighting costs about one-tenth of a cent per hour. As near as I can estimate from our own experience with electric lighting, it is not far from one cent per hour, which would be, roughly, ten times the cost of oil lighting, not counting the cost of the renewal of the plant, or as my impression is, the cost of repairs to oil lamps-I am not certain about that.

The President:-As I understand, the cost of electric lamps in a car is materially less. I am speaking of the lamps themselves. Is not that the case?

Mr. Blodgetr:- The fitting of the car with oil lamps, will cost anywhere from $\$ 12$ to $\$ 50$ for each lamp, and if, as is usual, from twelve to fifteen lamps are put into a car, it would cost not less than $\$ 150$ for the oil lamps put in a car. The cost for an equal number of electric lamps would not be over $\$ 24$.

Mr. Phelps:-May I ask Mr. Blodgett, in making up the figures of cost of electric lighting, if he first entered the item of depreciation of the storage battery plant-its consumption?

Mr. Blodgetr :- It is difficult for me to estimate to just what that would be. The assumption was made that the batteries would last two years.

Mr. Phelps:-Then your figures proceed on that basis, the renewal of the batteries in two years?

Mr. Blodgetr :-I think that was the estimate; renewing them every two years. I ought perhaps to say, regarding these figures, that the time during which the apparatus has been operated, is so short, that the figures are only roughly approximate. The cost may prove to be very much less than this, and possibly, but not probably, is seems to me, somewhat greater. 
Mr. RIEs :- What proportion of the cost for lighting is due to the cost of handling the batteries, and what proportion is due to the interest on the installation?

Mr. Blodgetr:-There is no expense for handling the battery. The charging of it has been done thus far at the rate of seventyfive cents per car per day. I think it will cost somewhat more in the future, as the electric lighting companies who are doing it, complain that this rate does not pay the cost. Possibly it may cost $\$ 1.50$ a day per car for the charge.

Mr. RIEs :-According to that, the cost per lamp simply for the charging, would be about five cents?

Mr. BlodgetT :-Roughly that.

Mr. Bracken:-I can state that the cost of charging Julien cells per car is about thirty-three cents. The Weston Company charges one dollar and a half per car. I may say here that about six or seven days ago I met Mr. Pullman. I remarked, among other things, that the chief objection to lighting railroad trains by electricity seemed to be the expense, and he said-of course it was his opinion, but it has considerable weight, coming from a man of his experience-he said that the mere matter of expense would not stand in the way of ligthing by storage batteries, if it were proved to be practicable. Then we have the opinion of another gentleman who has had a great deal of experience, Dr. Dudley, of the Pennsylvania Railroad. Two years ago, that road experimented with storage batteries. Dr. Dudley has come to the conclusion, as a result of his experience, that the only thing now wanting to induce the Pennsylvania road to adopt the storage batteries was a simple connector of a cell whereby a plate could be removed which showed any disposition to deteriorate. So far we have been unable to get a connector that we could remove and adjust without considerable trouble in order to remove a defective plate. The chief objection made by parties in relation to lighting by storage batteries is the fact of cost-the first and the only objection; but experienced railroad men, as I have told you, do not seem to regard that as a serious objection any more than is the cost of a parlor car in comparison with an ordinary passenger car.

The Secretary :-I would like to inquire whether the objection to the expense is on account of the original cost of the plant or the cost of the running of it, after it is installed ?

Mr. BlodgetT :--I think, Mr. President, that both those arguments have been used as an objection to the introduction of elec- 
tric lighting; but if account is taken of the amount of light furnished by the electric light in comparison with gas or oil, that item of expense will disappear. If people will be content to have as little electric light as they will get from oil or gas, the expense, it seems to me, would be no greater, but the change in lighting is the excuse for getting three or four times as much light as is furnished by the old systems. In that respect the cost of electric lighting is made to assume a very undue proportion in relation to the cost of other methods of illumination, and there, it seems to me, is a very prominent reason why the electric light fails to make greater progress - that with the change, is demanded an enormous increase of light.

Mr. Lockwood:-Mr. Blodgett, among other statements in his paper, remarked upon a method of introducing first, only a comparatively small number of cells, and as exhaustion supervenes in those cells, a few more are introduced, and then a few more. I would like to ask him whether experience has demonstrated that to be a better method than introducing the full number of cells at first and with them a certain artificial resistance, and then switching out the resistance as occasion would demand?

Mr. Blodgett :-I would say in answer to the question that the number of cells was never varied more than four on each side. We started with twenty-seven cells in series and ended with thirty in series. We have run trains on trips with the whole thirty cells in series, and I might say with substantially the same results. There was no opportunity for me to determine by experiment, previous to running these trains, any of the questions which have come up in relation to it. The electromotive force of charged cells is rightly two volts, but when they are freshly charged it is somewhat more than that; I think some of the publications on the subject state it at $2 \frac{1}{2}$ volts. In order not to have the undesirable effect of burning out a number of lamps by running a greater current than they would bear, this arrangement of switches was made. Thus far we have no unfavorable results. In one or two instances, when that was tried, it did seem to ine as though the lights were not quite so good at the end of a trip as when we had started with twenty-seven cells in series, and four remaining cells to be put in from time to time, as the candle power of the lamps began slowly to diminish; but I am not prepared to speak decidedly on that question either way'. 
Mr. Lockwood:-Does not the resistance of the cells vary as their E. M. F. runs down?

Mr. Blodgetr :-I think that is probably true.

Mr. Lockwood:-That is the point I was trying to get at, as to whether it was a decided advantage to keep those cells included in the circuit, even though they were to a certain extent exhausted, and even though you got the benefit of the new cells by so doing.

Mr. BlodgetT:-I think further experiment is necessary in order to enable one to answer that question.

Mr. Mallloux :-I think I can give some information on that subject to Mr. Lockwood. I hardly think the question needs to be answered, because probably everyone who has experimented with primary batteries, knows that you can take freshly charged bichromate cells-say Fuller cells, and if you wish to make a constant difference of potential across a certain part of the circuit you can use a part of them at first, and as they weaken add more to the circuit. The only difference that it makes, as far as I know, is that you are adding cells which have not been worked so much, and they would not give out so quickly as the others. In others words, the number of ampere hours that would be obtained from these freshly added cells would not be so great, and in practice, using them, as Mr. Blodgett states, those cells that are added last are never discharged to such an extent as the others, consequently there is some energy left in them at the end of the trip. It would doubtless be practicable to use resistance as Mr. Lockwood suggests, and to discharge the cells, but there would be nothing gained by it, except, perhaps the inconvenience of handling the resistance. It is much simpler to use only those cells which are necessary to get the proper electromotive force, and to add cells as the electromotive falls down; and those cells which are put in last if they are not fully discharged, are in much better condition because we find in working storage batteries that it is not well to charge a storage battery too much. Indeed, I may say that the greatest grievance we have against storage batteries, is that the public will insist on trying to give to the storage battery a greater capacity than the maker himself would like to have it go out for. The Julien Battery Company, with whom I have the honor of being associated, makes a cell of one hundred and twenty-five ampere hours, which is catalogued for that rate; but we find numerous people who have endeavored to use it for street 
car traction and for various other purposes, and who have come to us telling us that they get from 180 to 200 ampere hours out of the cells, thinking they were giving us very valuable and much coveted information. But while we admire their enterprise, at the same time we always deem it prudent to tell them that they really need not fully exhaust their cells, that they had better restrict them to the capacity which the manufacturer denotes. We tell them, if they persist in using a 125 cell to a capacity of 180, we shall have to rescind the guaranty of two years that we give upon a cell. The fact of the matter is, that there is an intimate connection between the life of a cell and the way in which it is handled by the person who buys it, and, as I just said, the trouble comes mainly from the fact that the cells are over used. It is not the use of the cell, but it is the abuse of it that is always responsible for its giving out. As long as a cell is not fully discharged, the peroxide on the positive plate is to a certain extent infiltrated with sulphate that has been produced by the chemical reaction during discharge. But if we proceed so far that a large quantity of sulphate becomes formed at the expense of the peroxide, then we shall find that when the process of discharging is again resumed, that we can no longer reconvert that mass of sulphate into peroxide, and wherever the process of charging is stopped, there will be a process going on by which that sulphate will undergo a fresh reaction and become hardened, and the consequence will be that a line of demarcation is produced and a scale results. That scale is the beginning of trouble and a great many times the beginning of the end with a great many storage bat teries. This is a defect which is inherent in a great many storage oatteries using lead. Now, if we do not discharge the battery too much, we leave a sufficient mass of peroxide to add conductivity to the mass of sulphate, so that the process of discharging can proceed without difficulty. That is why it is more difficult to use the three or four cells which are added, and which are necessary to rejuvenate the force of the rest than to discharge them all equally. Those three cells are not discharged so much as the others, consequently they are not so much used, and, by the process of changing the trays once in a while, so that they all have this little holiday at the end of the trip, the amount of life thus given to the battery could be averaged through the whole number of them.

Mr. Wetzler :-Mr. Blodgett, in his paper, enumerates the 
different methods by which trains may be lighted, and in all of them except one, in connection with which he mentions the primary battery, we find that where we want a steady light the storage battery must be added to the equipment. Although he says he has had experience with only one of this kind, I would like to ask if he has formed any opinion upon the ultimate shape which the application of the storage battery will assume-whether it will be charged on the train or whether it will be charged at the terminus only.

Mr. BlodgetT:- That is rather a hard question to answer, since it must be on my part merely a matter of opinion. It does seem to me, however, that some one will find a way by which the battery can be charged on the train with regularity and with good results. If that can be done, it will much simplify the use of the storage battery, since the charging will take no extra time, and would, it seems to me, give better results than being obliged to charge the batteries every day or every other day. I know of no practical device at present to accomplish that result. Its success in England is due to the different arrangement of the cars. Most of the English cars on which it has been tried, have, in place of our trucks at either end of the car, only a single axle and a pair of wheels which are fixed with sufficient rigidity, so that they can run a dynamo shaft. But American cars have a swinging truck at each end from which it is difficult to convey power to any other piece of machinery while going around curves.

Mr. RIEs :-Mr. Wetzler has asked almost the same question that I was about to propound, and Mr. Blodgett has answered it so far as the present state of knowledge is concerned. But the feature that Mr. Blodgett just mentioned: namely the difficulty of making connection between the axle and other mechanism is, of course, one of those difficulties which only time can overcome. But it seems to me that instead of taking a secondary battery, instead of equipping in such a way that the battery must either be removed from the car, or that the car must be side-tracked and remain idle for eight hours more or less, a system could be devised in which the battery carried by the car was a permanent fixture and received its charge during the time that the train was running on down grades by a dynamo, driven by the surplus energy of momentum of the train itself, whereby the direct application of steam co-operating with the dynamo can be obviated. One of the greatest objections to these various steam 
heating systems, is that in order to maintain a separate system of heating, the locomotive would have to be drawn upon very considerably, and that is found somewhat impracticable. The very same objection would obtain in the use of a battery; but on large trunk lines, there are numerous trains in which it would seem that the momentum which is in excess of the speed at which it is desired to run could be readily converted into chemical energy, which could be stored in a battery until required. It might be so arranged as to receive all the current that is generated at regular intervals, and in a simple way this could be made to furnish the current for lighting. Several of the members here would be pleased to know whether Mr. Blodgett has had any experience with such system, or whether he knows of any such system being proposed for utilizing the electric current for lighting railway trains.

Mr. Blodgett :-I do not, Mr. President, know of any such system. It seems to me that the amount of power required to light a train electrically is so very small that it would not be a serious question. If the locomotive is so nearly worked up to its full capacity that it could not spare two or three horse-power more when running between six hundred and seven hundred perhaps, or possibly eight hundred or nine hundred horse-power, if it could not spare two or three more for lighting the train, then it would be necessary to attach a second locomotive to keep up the speed of the train around the curves. The belief that the heating of the train would make a draft on the locomotive has been brought up as an objection, but practical experiments have failed to show that steam heating does have such an effect. The amount of steam heating required for a train is very small, and the pressure of two to five pounds even in very cold weather with proper piping of the cars and proper connections, will sufficiently heat the train, and when the locomotive carries 160 pounds steam, as the best kind of locomotives do, a pound or two more is not a serious percentage of loss.

Mr. Lockwood:-I am very happy to add my little word of testimony to that of Mr. Pope, as to the efficiency and perfection of the system of electric lighting which now obtains on the afternoon train, between here and Boston. It is some three months since I first travelled on that train, since the lighting and steam heating was introduced, and although I had heard it vaguely referred to in the papers, I had not experienced it myself 
before that; and it was with considerable doubt that I took my seat on the train that afternoon. Mr. Pope has remarked upon its advantages in going through tunnels. I must say, there is room for difference of opinion in regard to that. But as there are not many tunnels between here and Boston, it is not much of an objection nor much of an advantage upon that line, but it is a real pleasure to any one who likes to read upon the train, or who likes to see what his fellow passengers are doing, or who likes to eat intelligently, to travel upon a train lighted with incandescent electric lamps excited, not necessarily by a Julien battery, but by any good secondary battery. I notice with some grief that the gentlemen here have been persistently calling such batteries accumulators and storage batteries. There perhaps may be a word or two which might pertinently be said referring to the English installation, which Mr. Blodgett has mentioned. The system which is in use on the London and South Coast Railway is, as as we have heard, operated by the shafts of their cars, and, as Mr. Blodgett has said, they do not use trucks at all, simply a pair of wheels on each axle. The method of getting the power to the dynamo is by using an counter-extra shaft and running two belts. That is a point worthy of notice-a pulley on each side of the train, running two belts to the counter-shaft, and although it was not done so at first, they have recently adopted also two belts from the counter-shaft to the dynamo axle, putting the pulley on both ends so as to insure running at all times. They also have a very ingenious method of keeping the belt stretched by screws at both ends, both operated by one handle by means of a worm gear which pushes the countershaft into a position diagonally to or triangularly from, the dynamo axle and from the first main axle of the car, so that it tightens up both series of belts, at the same time. It seems to me there is something which is more theoretically perfect in such a system, which carrying the original power along with it, may also carry and excite batteries, to maintain the light when the dynamo is at rest, than there is in any other system. Of course, the objection that is stated against that in this country is very weighty; but I think the time will come when our cars, as well as our houses, our stores, and our business blocks, will be properly fitted for the use of every electrical appliance, with, I hope, one exception. While we want all the light we can get while we are travelling (except in tunnels,) we do not want, at least I do not want, ever to be 
telephoned to, or to telephone a message, or to be telegraphed to, or to send a telegraphic message to anybody while I am on the train. I think, all who have to work as hard as you do, will agree with me on that point. The steamship or the train is now our sole refuge. (Laughter and applause.) We want at least one haven of rest where the wicked will cease from troubling. One gentleman questions in some degree, whether using the power of the locomotive to operate the shafts of the dynamo would not detract somewhat from the tractive power of the locomotive. $\mathrm{Mr}$. Blodgett answered it very well, as I thought; but that question appears to have already settled itself, when we consider the English method of getting light on a train. I read very carefully the paper written by one of the inventors of that system before the Institute of Civil Engineers in London on that point, and, while it may be that he is wilfully disguising the truth, he being an inventor, yet it is a fact that he says nothing about any such loss of power, if it occurs. He does not seem to intimate that the locomotive goes any slower between London and Brighton, or that it uses any more coal, or that it uses any more steam. It may be that it does. At all events the locomotive does not appear to feel the extra strain upon it at all. It gets there just the same. Without any disposition to criticise, I notice one statement of $\mathrm{Mr}$. Blodgett that was very interesting, yet I do not know that it completely covers the ground. He remarked, when discussing the difference of cost, which seemed to be considerably in favor of oil over electricity, that the amount of light which we used to have under the old oil administration, before Mr. Cleveland was elected, (Laughter) was not half as much as we get now. Well, we all know that is true. We did not get one-half or one-tenth as much light as we get now. It was worth one good pair of eyes to try to read for ten miles. But in view of the fact that when we get a certain amount of light from a certain amount of electrical power, it takes a very little more electrical power to bring the light up to a much higher degree of brilliancy, it is a question with me whether, if we brought the light down to the old standard, the cost would be very much diminished. I rather doubt it.

Mr. Blodgett :- It may be, Mr. President, that I did not make that part of my statement sufficiently clear. I meant to be understood as saying that, if we put in lamps enough in a car only to light the car to the same degree of brilliancy that was obtained by oil, then the cost would be no more than that of oil; not by 
using the same number of lamps we are at present using, but by putting in a less number. It is true that, if you decrease the candle-power of the lamps, you use a larger proportion of energy to produce that candle-power-a larger proportion per candlepower than if they are running at a higher candle-power. But using a less number of lamps and lighting the car the same as it was lighted with oil, the cost, I think, would be no greater than with oil. We ought to consider that, in a lamp of say sixteen candle-power, perhaps one-half of the light and perhaps a larger portion is cut off from available use by the fixture of the lamp itself. In the electric lamp there.is no fixture to cast a shadow or absorb the light, and withdraw it from a useful purpose.

Mr. Lockwood:-I am very glad to get that explanation. The last paragraph of this most interesting paper reads as follows:

Oil lamps, and stoves in cars, must follow where the old couplers and hand brakes for passenger trains have gone in this country, until electricity and steam heat have made the roasting alive of scores of people pinned fast in a railroad wreck as impossible as the air brake and Miller platform have made the telescoping of a train into a shapeless mass of ruins, as happened formerly so often. Not many years hence, we may well hope, one will be as uncommon as the other.

A great English poet once said: "Hope springs eternal in the human breast." And I am quite sure that if we get all the incandescent lamps that we can, and light our train as brilliantly as possible, and leave out the stoves, that the railroad companies will still find some way to get square with us. They will put bridges askew or build tin bridges where iron bridges should be placed.

What I wanted to mention was that there are people to whose perversity I feel that I cannot do justice. I refer to the person who deliberately pulls up his window on a dusty day in front of you, and in that respect I must say our English cousins who are generally behind us are ahead of us. Not only did they start train lighting long before we did, and run it to a greater degree of perfection than we did, but they are using the window which we are now using for street cars. Now if car builders will adopt that sort of window so that we could lower it instead of raising it, it would do away with the blasphemous thoughts which arise in our breasts on many occasions.

Mr. Wetzler :-Mr. Ries has led the discussion in a direction which I think would still bear pursuing a little further. He refers to the fact that where storage batteries are used on trains, 
some account should be taken of a method by which trains running down grade shall be enabled to charge batteries; that these means must to a certain extent be automatic seems self-evident, and I believe Mr. Ries's modesty is such that he has withheld something from us that would shed some light upon the subject. I would, therefore, like to hear his views on this question.

Mr. RIss:--In respect to Mr. Wetzler's kind suggestion, I would state that while not fully at liberty to mention what he undoubtedly refers to, I might say that I have given some attention to this matter of accumulating the surplus energy of a train and storing it in the form of electrical energy, and among the problems was the one that Mr. Blodgett suggested in reference to the axle of the car, which I believe we have solved. There is also another objectioin, and that is, that as the speed of the train slackens, naturally, the electromotive force of the current produced decreases and means must be provided for maintaining that up to the standard, so that the batteries will not discharge through the generator. There are other matters which, of course, suggest themselves in this connection, but we might say in a general way this: Taking the ordinary trunk line road, we find a great many with very steep gradients; the energy of the locomotive used in propelling a train up a steep incline is ordinarily wasted on the next descending grade by the energy of the train being checked and further steam applied to check it by means of the brakes. Now, the energy of a train can as well be checked by attaching a generator to the axle directly or by means of belts, the direct connection being preferable, and forcing that to generate more or less current. In order to accomplish this I have devised a form of pendulum switch-or any other form of gravity switch will answer-whereby the amount of current produced by a generator for charging the battery is directly proportional to the inclination of the grade; so that as long as the train is running on a level the field magnet coils of the generator are open, and the magnetic saturation can be increased or diminished at will. The number of coils thrown into the circuit is automatically adjusted by means of this switch before mentioned, whereby, when the train is running down on a steeper incline than before, it makes a stronger magnetic field, retards a greater proportion of the energy of the train and generates a correspondingly increased volume of current which is stored in a battery for use as required. Now, the greatest expense in the present method of lighting railroad trains by 
batteries seems to be in the cost of charging. A further expense in some systems arises from the fact of using a double set of batteries, one of which is being charged while the other is being worked-both of which can be dispensed with-as well as the cost of handling. By means of a system of this kind the battery when once in position is self-charging, so to speak. A sufficent number of cells are used to give you the requisite number of ampere hours, and the number of cells that we do use, of course, will be determined by the number of hours that your train is running. The generator is so arranged that, as before stated, in running on a small incline, the field magnet strength is slightly decreased, but as the speed of the train slackens, in case of wanting to come to a stop, the field magnet strength is automatically increased. We have both a gravity switch and governor in this arrangement, so that the electromotive force is produced until the speed of the train has very nearly ceased. In that way the battery will always have a sufficient supply of current in reserve, whether it be used for lighting or braking or whatever other applications you may wish to employ. The system, of course, is as yet somewhat incomplete, but is being developed, and I hope at some future time to go more into detail in regard to it.

Mr. Mallloux:-As those who have preceded me remarked, we have in this branch of the discussion a most interesting and perhaps timely topic, and I can state here, semi-officially that the Julien company is, and has been for some time actively engaged in the study of that very question. I have had several communications upon the subject from Mr. Julien, who is now abroad, besides having given a great deal of attention to the matter myself.

I must say that I do not quite agree with Mr. Ries, in his views on the subject of utilizing only wasted energy. This idea of using waste energy is very good in theory, but it does not always work in practice. A car starts from here to go to St. Louis, or some distant point, a trip requiring a considerable length of time. Now, what a practical lighting man, like Mr. Blodgett, wants to know is, how many hours of artificial light will be required; how many lighting hours of electricity he has got to supply that want, and with him it is of far more importance to be able to get at so many ampere hours per mile, than it is to take his chances of getting it at the next grade, or giving the engine a spurt so as to get it on going down a grade. Therefore, I believe that as the 
amount of energy which is constantly being drawn upon, in a car making a long trip is so small, that it will be better in practice to content ourselves in drawing it directly, without paying attention to what is being saved or to what might be saved. In a car travelling all day, it is safe to say that excluding the time of stoppages, we have something like twenty or twenty-two hours of travel. Now, if we so arrange the apparatus that we can draw a small current for those twenty-two hours, it is quite evident that the draft might be large, and as Mr. Lockwood, very aptly remarked, doubtless the strain on the constitution of the iron horse might be very appreciable. On the other hand the hours of lighting will never be so long, because in sleeping cars after certain hours there are very few lights in use. The policy which the Julien company has pursued has been to aim at simplicity and to so arrange apparatus that it can be put into the hands of whomsoever may be called upon to direct its application, and with that in view we have sought to eliminate as far as possible, all elements of complication in the way of regulating gear. Not long ago, I visited a train of which Mr. Blodgett spoke in his paper, in which the attempt is made to get motive power from the axle. I found, on arriving there, that the gentleman had almost converted the baggage car into a machine shop. He had very complicated machinery below, and upon entering the car I found that he had very complicated machinery inside. He informed me that the system worked very nicely indeed. I did not wonder. It ought to work beautifully with the amount of complication that he succeeded in introducing into it. But I doubt very much whether the average railroad manager, or superintendent, or master mechanic, or whoever the official is that is charged with the lighting of cars, would be satisfied to accept the introduction of such a system on his road. It seems also that on roads having considerable traffic it would be necessary for them to provide an additional baggage car, because there is no space left in the compartment in which the machinery is put, and it would be cheaper to go the whole extent, put in power, make the car a little smaller, and call it a lighting car.

The system at which, it seems to me, we should aim, is a system in which there is little or no complication. As you all know, the fact must be borne in mind, that a train will run anywhere from ten to fifty miles an hour. Now, in order to compass the great variations, consequent on such a change of speed, the minds 
of electricians have been filled with numerous devices of resistance regulators, etc. Now, I do not see that any system involving the application of complicated regulating devices of that kind can hope to be successful. We must have a system in which the mechanism is so simple that there are practically no details to it. If we can have a dynamo that will take care of itself, we are working in the right direction. I remember that at a previous meeting, during a discussion on electric street cars, Mr. Field remarked on the sparking of the dynamo, that he proposed to let the sparking take care of itself. Now, I think that is the keynote of what we should do in the lighting of cars. Undoubtedly the day of lighting cars with an axle dynamo is coming, and when it has come, we shall find that the proper system is that in which the dynamo is taking care of itself, without having to call upon a thousand and one details of machinery and clock-work to assist in taking care of its work.

Mr. RIEs :-Mr. Mailloux made a very forcible argument in support of the direct dynamo connection for generating purposes. I fully agree with him, that that would be the simplest as well as the best system to adopt in practice on such roads where for certain reasons the momentum system suggested before would not be applicable. But it is a well known fact that a great deal of power is lost every day on our trunk line roads, from the very cause mentioned, and the secondary battery presents to us a useful and simple means of converting at least a portion of that energy into use. Now, I do not advocate this system on level or substantially level roads. It is only in cases where the advantages would justify its adoption that I would recommend it. For ordinary roads, however, the direct dynamo and battery connection as recommended by $\mathrm{Mr}$. Mailloux, is perfectly proper and probably the best plan to adopt.

Mr. Pendleton:-While listening to the remarks on the accumulator and the care with which it has been attempted to work out a system, simple and effective, for the purpose of lighting railway cars, I failed to see where there is, in the necessities of the application, room for very great study. The principle of the accumulator is that one ounce of material will hold a certain quantity of chemical energy. That was the feature of the Faure battery of 1880 , and as nature is generally regular in her habits, we may calculate that one ounce in 1880 , of peroxide of lead would hold as much nearly, as it will at the present time. There have 
been certain improvements made, however, in the accumulator, of decreased resistance, and capacity increased relatively to the weight of the battery; so that at the present time there is improvement, but the basic element remains the same. The feature in the storage battery appears to me to be one of inherent character which is difficult to overcome, except by the intelligent application which Mr. Blodgett has to-night mentioned of switching in additional cells. We all know the effect if the electromotive force of the battery fails to be discharged. There is another and unfortunate effect, in that the resistance of the lamp is also increasing; requiring some means of keeping up the electromotive force and keeping down the resistance of the incandescent lamp. Some years ago that feature troubled me considerably, as to the application of storage battery plants for general use, and I felt that the storage battery when applied would find its great use in power, in the application to street cars, in the application to motors, etc., and which is now being developed to an extent which makes the subject very interesting. We have seen in our streets a car, the mechanical construction of which being completed in a foreign country was not exactly suited to our railways. I do not know whether it has yet been brought to a point of perfection. But at any rate, competent electricians riding on the car stated that the defects were purely mechanical and that the electrical performance of the car ought to satisfy anyone informed upon the subject of electrical work and the action of the motor. A number of cars are being built, and what was a dream among electricians, six or twelve months ago, will very shortly be in practical use. Railroad men generally are very slow to take hold of improvements in their different systems. So many unfortunate experiments make them weary, and it is only after most thorough and careful tests that they are disposed to adopt new devices.

In the matter of lighting cars by electricity, I think Mr. Mailloux is at fault in stating that it has not before been accomplished in this country. I recollect the Pennsylvania Railway Company making experiments in 1883 . I paid but little attention to them. I know also that in England in 1882 the London and Brighton train was lighted by accumulators, and so continued for several years and may, for all I know, be so lighted at the present time. There is nothing new in the matter. The fact has been demonstrated that the Julien battery is a well manufactured, good accu- 
mulator for the purpose-as good as any that is made. The claims for efficiency are high. I hardly believe that it is intended that $85 \%$ as claimed is the efficiency of the battery. I know of recent tests made where the efficiency, the return of power, was determined to be 65 per cent. and was considered very satisfactory. I certainly found it so, because it proved a belief that I had that the true efficiency of an accumulator was 50 per cent. I recollect at a former meeting of this society when I stated that fact, it was doubted. With 65 or 66 per cent. return from the battery, and allowing 15 per cent. loss in the motor; this 50 per cent. efficiency is realized in the use of the storage battery for propulsion purposes, and as the tests were made under the supervision of your late president, Mr. Pope, I know that they are thoroughly reliable. It is a return that must bring the battery for the purpose of propelling cars into very general use, and I know already of several cars being built for the purpose of testing the matter.

Mr. Maillodx :-I would like to make a few remarks which it would be well to place on the record in this connection, as $\mathrm{Mr}$. Pendleton, my friend and esteemed colleague, has made some remarks which refer to the Julien battery of which I am one of the representatives here. With due respect to Mr. Pendleton, I must say that he likes to live in the past. He has been pleased to go back to the time of Faure and tell us that an ounce of active matter was capable of storing a certain amount of energy. I would like to take him back further, to the time of Plantè, and show him that an ounce of matter also had the power to store a certain amount of energy, and I may even go further back than that. An ounce of matter in a storage battery-peroxide-is capable of holding a certain amount of energy. Now, with regard to the efficiency, I would like to call the gentleman's attention to the fact that efficiency in train lighting is quite a different thing from efficiency in the case of motor traction; and as I told him at the meeting where we had the discussion on electric motors, it is quite important to take into consideration the successive transformations that the energy has to undergo. It is necessary that we should know where the final absorption of the energy takes place. If we are going to take the energy and transform it several times, each time we have to take into account a coefficient of loss which he fails to take into consideration. I think we can easily show that the efficiency of electrical energy in lighting is much higher than 65 per cent. It is true that there is nothing 
new with regard to the application of electricity to train lighting, using storage batteries or any other means. At the same time anybody who has studied the question realizes that there are many different conditions to meet, and that because it is not new, does not prove that it is undeserving of our attention. There are in it some problems which call for the highest knowledge of the electrician, and the highest skill of the engineer, and I think it is well to bear those subjects in mind.

The President :- I think we have spent a very pleasant and profitable evening, and we are greatly indebted to Mr. Blodgett for the admirable paper he presented to us, and which has brought out so valuable a discussion.

There being no further discussion of the subject, I declare the meeting adjourned. 